\title{
New Homologues Series of Heterocyclic Schiff Base Ester: Synthesis and Characterization
}

\author{
Yee-Ting Chong, ${ }^{1}$ Norazilawati Muhamad Sarih,, ${ }^{1}$ Sie-Tiong Ha, ${ }^{2}$ \\ and Md. Rezaul Karim Sheikh ${ }^{3}$ \\ ${ }^{1}$ Department of Chemistry, Faculty of Science, University of Malaya, 50603 Kuala Lumpur, Malaysia \\ ${ }^{2}$ Department of Chemical Science, Universiti Tunku Abdul Rahman, Jalan Universiti, Bandar Barat, 31900 Kampar, Perak, Malaysia \\ ${ }^{3}$ Department of Applied Chemistry \& Chemical Engineering, University of Rajshahi, Rajshahi 6205, Bangladesh
}

Correspondence should be addressed to Yee-Ting Chong; chongyt@siswa.um.edu.my and

Norazilawati Muhamad Sarih; nmsarih@um.edu.my

Received 28 July 2016; Revised 19 October 2016; Accepted 10 November 2016

Academic Editor: Jan Skov Pedersen

Copyright (C) 2016 Yee-Ting Chong et al. This is an open access article distributed under the Creative Commons Attribution License, which permits unrestricted use, distribution, and reproduction in any medium, provided the original work is properly cited.

\begin{abstract}
A homologous series of liquid crystal bearing with heterocyclic thiophene Schiff base ester with alkanoyloxy chain $\left(\mathrm{CH}_{3}\left(\mathrm{CH}_{2}\right)_{n} \mathrm{COO}-\right.$, where $\left.n=4,6,8,10,12,14,16\right)$ was successfully synthesized through the modification of some reported methods. The structural information of these compounds was isolated and characterized through some spectroscopic techniques, such as FTIR, ${ }^{1} \mathrm{H}$, and ${ }^{13} \mathrm{C}$ NMR and elemental analysis. Textural observation was carried out using a polarizing optical microscope $(\mathrm{POM})$ over heating and cooling cycles. It was found that all synthesized compounds (3a-g) exhibited an enantiotropic nematic phase upon the heating and cooling cycle with high thermal stability. Moreover, a characteristic bar transition texture was observed for compounds $\mathbf{3} \mathbf{f}$ and $\mathbf{3 g}$ which have shown transition of nematic-to-smectic $\mathrm{C}$ phase. This has been further confirmed by obtaining relative phase transition temperature using the differential scanning calorimetry (DSC).
\end{abstract}

\section{Introduction}

The design and investigation of new mesogens are fast garnering interest from liquid crystal researchers [1]. Among the synthesized compounds, thermotropic liquid crystal has brought some interests to the researcher. Thermotropic liquid crystalline compounds possess a number of unique properties that are of immense value. Tremendous efforts were made on designing of new compounds. It was found that the molecules with an extended rod-like shape often greatly exhibit thermotropic liquid crystalline phase $[2,3]$. A significant amount of work [4-7] has been carried out on rodshaped liquid crystals, which ultimately led to the application of LC displays. Its molecules could be arranged in smectic layers, making them a viable possibility for technological products [4]. Rod-like liquid crystals are generally categorized into two categories, which are liquid-like smectics (SmA and $\mathrm{SmC}$ ) and crystal-like smectics (SmB, SmE, SmK, or
SmG), where both are based on different distributions on its molecular center of mass [5].

New mesogens with heterocyclic compounds such as benzothiazole $[6,8,9]$, benzoxazole [10], 1,2,4-oxadiazole [11], pyrimidine [12], and pyrazole [13] had attracted the interest of scientists, as the insertion of heteroatom will strongly influence the formation of mesomorphic phases. These heterocyclic structures generally incorporate unsaturated atoms, such as $\mathrm{O}, \mathrm{N}$, or $\mathrm{S}$, and due to the high electronegativity of these atoms, it often results in reduced symmetry of the molecules and creates a stronger polar induction. The use of unique heterocyclic moieties to produce materials of low symmetry or/and nonplanar structures can be technologically important for liquid crystal applications [14].

There are lots of the compound previously published being synthesized with the insertion of the above heterocyclic ring. However, the reported literatures on the thiophene 

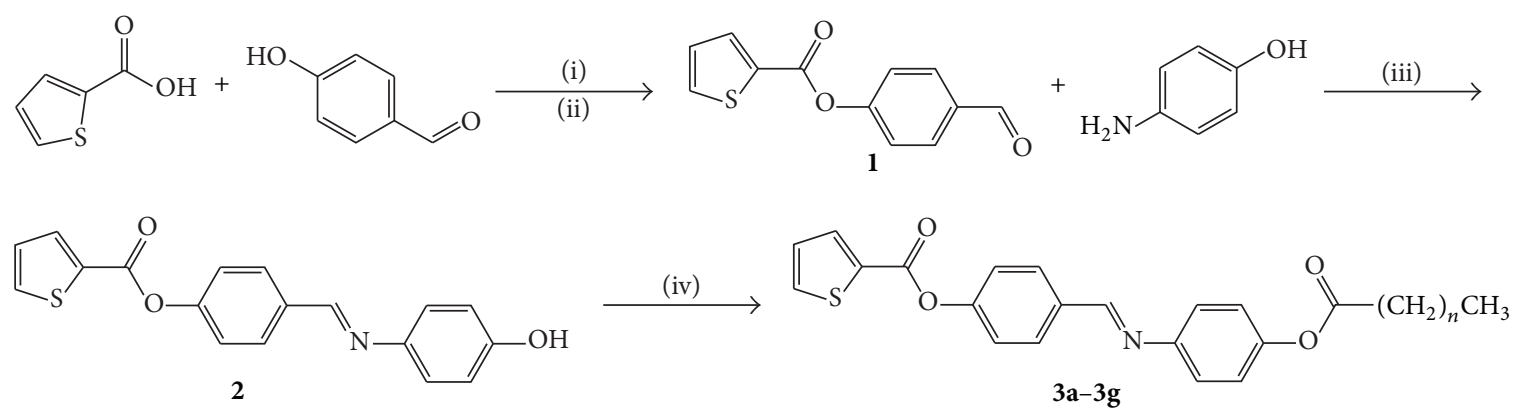

Scheme 1: Synthetic route for the target compounds: (i) $\mathrm{SOCl}_{2}$; (ii) benzene, pyridine; (iii) ethanol, acetic acid (cat.); (iv) DCC, DMAP, dichloromethane, and dimethylformamide. Yield of 3a (19\%), 3b (23\%), 3c (29\%), 3d (35\%), 3e (42\%), 3f (39\%), and 3g (40\%), where $n=4$ (3a), 6 (3b), 8 (3c), 10 (3d), $12(\mathbf{3 e}), 14(\mathbf{3 f})$ and $16(\mathbf{3 g})$.

based liquid crystal are still rare and there are great potential for further investigation of this kind. Despite the presence of heteroatom, $\mathrm{S}$ in the thiophene ring, it was also a fivemembered heterocyclic compound. The previous works have shown that the five-membered heterocyclic compounds were able to show mesomorphic properties. The presence of a heteroatom can cause profound changes in mesomorphic behavior, due to the differences in their electronegativity in relation to carbon or through changes in molecular geometry $[15,16]$.

In this paper, we will report a new homologous series of thiophene-2-carboxylate derivative liquid crystals (Scheme 1). The derivatives possess three core units (one thiophene and two phenyl rings) and are connected via a Schiff base and ester linkers, which increases both the molecular broadness and anisotropy.

\section{Experimental}

2.1. Materials. Decanoic acid, dodecanoic acid, tetradecanoic acid, hexadecanoic acid, octadecanoic acid, 4-aminophenol, and thionyl chloride $\left(\mathrm{SOCl}_{2}\right)$ were purchased from Merck, while thiophene-2-carboxylic acid, octanoic acid, 4-hydroxybenzaldehyde, and 4-dimethylaminopyridine (DMAP) were procured from Sigma Aldrich. $N, N^{\prime}$-Dicyclohexylcarbodiimide (DCC) was purchased from Acros Organics (USA). All reagents and solvents were used as received without further purification.

2.2. Synthesis. The synthetic protocol towards the title compounds, 4-((4-n-alkanoyloxyphenyl)imino)methyl)phenyl thiophene-2-carboxylate (where $n=6,8,10,12,14,16,18)$, is illustrated in Scheme 1.

Synthesis of Compounds 1. 2-Thiophenecarboxylic (40 mmol) acid was dissolved in $20 \mathrm{~mL}$ of thionyl chloride in a round bottom flask. The reaction mixture was allowed to reflux for 3 hours. Upon completion of the reaction, the excess of thionyl chloride was allowed to evaporate. A mixture of 4-hydroxybenzaldehyde $(40 \mathrm{mmol})$ dissolved in $10 \mathrm{~mL}$ of pyridine and $40 \mathrm{~mL}$ of benzene was then added in slowly. The mixture was refluxed for 2 hours. The precipitate formed was then immediately filtered off and the resulting solution was left for evaporation. The crude precipitate was recrystallized from the mixture of chloroform and hexane in the ratio of $3: 1$.

Synthesis of Compound 2 [17]. Compound 1 (20 mmol) was dissolved in $40 \mathrm{~mL}$ absolute ethanol in a round-bottom flask and a mixture of ethanol and 4-aminophenol $(20 \mathrm{mmol})$ was added dropwise. The mixture was refluxed for 3 hours. The resulting hot solution was then cooled to room temperature and subsequently cooled to below $5^{\circ} \mathrm{C}$ for 1 hour to allow the solid precipitate out. The crude products were then recrystallized first with a mixture of chloroform and hexane in the ratio of $3: 1$ and further on with ethanol.

Synthesis of Compound 3 [17]. Compound 2 ( $2 \mathrm{mmol}$ ) was initially dissolved in a minimum amount of dimethylformamide (DMF) and added into a mixture of corresponding fatty acid $(2 \mathrm{mmol})$ and dimethylaminopyridine (DMAP) (0.2 mmol), which has been already dissolved in dichloromethane $(20 \mathrm{~mL}) . N, N^{\prime}$-Dicyclohexylcarbodiimide (DCC) $(2 \mathrm{mmol})$ in dichloromethane $(5 \mathrm{~mL})$ was added dropwise into the mixture upon stirring at $0^{\circ} \mathrm{C}$ for an hour and was then stirred at room temperature for another three hours. Finally, the mixture was filtered, and excess solvent was removed from the filtrate via evaporation. The white product was recrystallized first with a mixture of chloroform and hexane in the ratio of $3: 1$ and further with ethanol until its transition temperature remained constant. The purity was detected by the use of TLC with the chloroform as solvent.

2.3. Characterization. The percentage yield and analytical data of the representative compound $3 \mathrm{c}$ are as follows.

Yield: 29\%, IR ( $\left.\mathrm{KBr}, \mathrm{cm}^{-1}\right): 3077$ (aromatic C-H stretch), 2957, 2922, 2873, 2849 (aliphatic C-H stretch), 1728 (ester $\mathrm{C}=\mathrm{O}$ stretch), 1626 (imine $\mathrm{C}=\mathrm{N}$ stretch), 1602, $1468(\mathrm{C}=\mathrm{C}$ aromatic ring stretch), 1205, 1142 (ester C-O stretch), 864 (C-S-C stretch) ${ }^{1} \mathrm{H}$ NMR (400 MHz, $\left.\mathrm{CDCl}_{3}, \delta \mathrm{ppm}\right)$ : $0.87-0.91\left(\mathrm{t}, 3 \mathrm{H}, J=6.7 \mathrm{~Hz},-\mathrm{CH}_{2} \mathrm{CH}_{3}\right), 1.29-1.43(\mathrm{~m}$, $\left.12 \mathrm{H},-\mathrm{CH}_{2}\left(\mathrm{CH}_{2}\right)_{6} \mathrm{CH}_{3}\right), 1.73-1.80(\mathrm{qt}, 2 \mathrm{H}, J=7.5 \mathrm{~Hz},-$ $\mathrm{CH}_{2} \mathrm{CH}_{2} \mathrm{COO}-$ ), $2.55-2.58\left(\mathrm{t}, 2 \mathrm{H}, \mathrm{J}=7.5 \mathrm{~Hz},-\mathrm{CH}_{2} \mathrm{COO}-\right)$, $7.10-7.12(\mathrm{~d}, 2 \mathrm{H}, J=8.8 \mathrm{~Hz}, \mathrm{Ar}-\mathrm{H}), 7.19-7.21(\mathrm{t}, 1 \mathrm{H}, \bar{J}=4.3 \mathrm{~Hz}$, Th), 7.22-7.24 (d, 2H, J = 8.7 Hz, Ar-H), 7.34-7.36 (d, 2H, $=8.6 \mathrm{~Hz}, \mathrm{Ar}-\mathrm{H}), 7.69-7.70(\mathrm{~d}, 1 \mathrm{H}, J=4.9 \mathrm{~Hz}, \mathrm{Th}), 7.95-7.98$ 


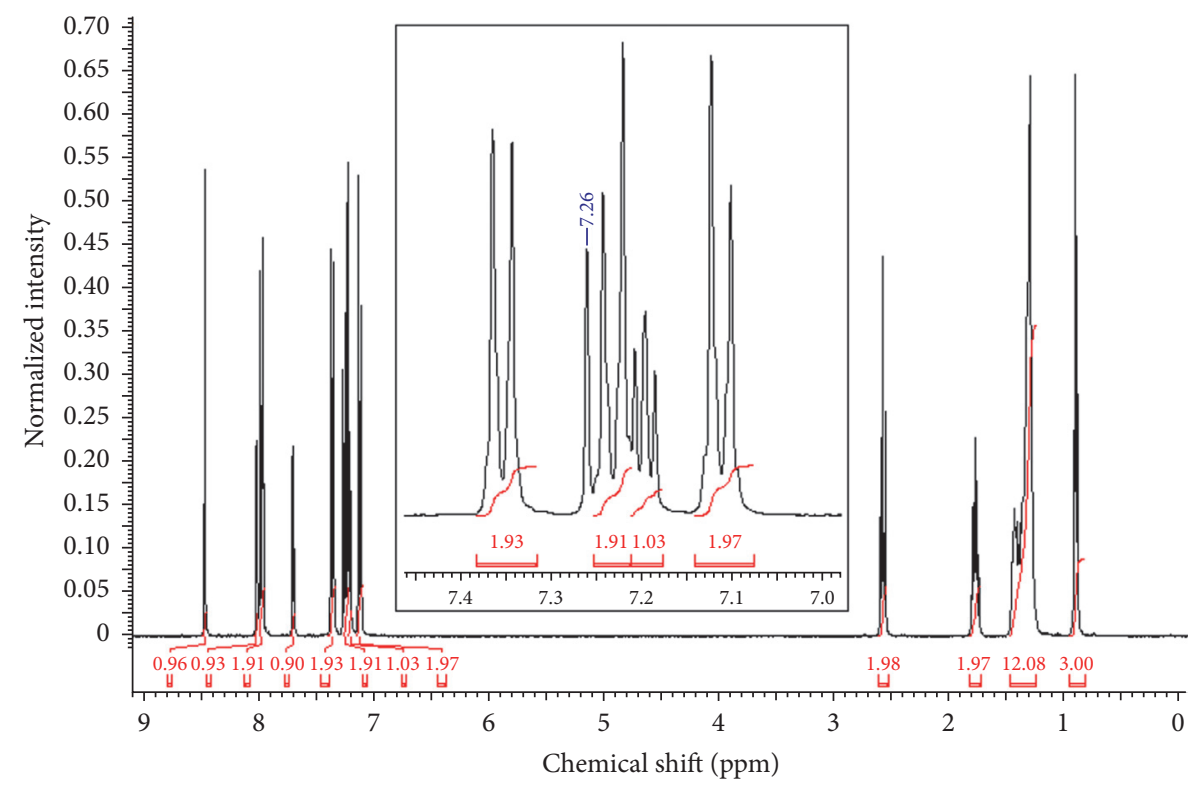

Figure 1: ${ }^{1} \mathrm{H}$ NMR spectra of $\mathbf{3 c}$.

(d, $2 \mathrm{H}, J=8.6 \mathrm{~Hz}, \mathrm{Ar}-\mathrm{H}), 8.00-8.01(\mathrm{~d}, 1 \mathrm{H}, J=3.7 \mathrm{~Hz}, \mathrm{Th})$, $8.46(\mathrm{~s}, 1 \mathrm{H}, \mathrm{CH}=\mathrm{N}),{ }^{13} \mathrm{C} \mathrm{NMR}\left(100 \mathrm{MHz}, \mathrm{CDCl}_{3}, \delta \mathrm{ppm}\right)$ : $14.12\left(-\mathrm{CH}_{3}\right), 22.68\left(-\mathrm{CH}_{2} \mathrm{CH}_{3}\right), 24.97\left(-\mathrm{CH}_{2} \mathrm{CH}_{2} \mathrm{COO}-\right)$, $29.13,29.27,29.43,31.87$ for methylene carbon $\left(-\left(\mathrm{CH}_{2}\right)-\right)$, 34.43 ( $\left.-\mathrm{CH}_{2} \mathrm{COO}-\right)$, 121.77. 122.14, 122.25, 128.14, 130.06, $132.54,133.85,133.95,134.98,148.98,149.38,152.97$, for aromatic carbon, $159.16(-\underline{\mathrm{CH}}=\mathrm{N}), 160.21,172.45$ (-COO), Anal. calcd. For $\mathrm{C}_{28} \mathrm{H}_{31} \mathrm{NO}_{4} \mathrm{~S}$ : C, 70.41\%, H, 6.54\%, N, 2.93\%: found: C, $70.42 \%, \mathrm{H}, 6.77 \%, \mathrm{~N}, 2.98 \%$.

\section{Results and Discussion}

All of the synthesized compounds showed the presence of a single spot in thin layer chromatography (TLC) plates. Structural elucidation of $3 \mathrm{c}$ is discussed as a representative compound from the homologous series, supported by the results of spectroscopic analysis (IR, ${ }^{1} \mathrm{H}$ and ${ }^{13} \mathrm{C}$ NMR).

Based on the FT-IR spectrum of $3 \mathbf{c}$, absorption peaks at $2957,2922,2873$, and $2849 \mathrm{~cm}^{-1}$ can be assigned to aliphatic groups, such as methyl $\left(\mathrm{CH}_{3}\right)$ and methylene $\left(\mathrm{CH}_{2}\right)$ groups in the long alkyl chain of the molecule. The presence of peaks at 1728,1205 , and $1142 \mathrm{~cm}^{-1}$ indicates the existence of the ester group $(\mathrm{C}=\mathrm{O})$. The absorption of the Schiff base group $(\mathrm{C}=\mathrm{N})$ was found at $1626 \mathrm{~cm}^{-1}$.

In the ${ }^{1} \mathrm{H}$ NMR spectrum of $3 \mathrm{c}$ (Figure 1), the triplet at $\delta=0.87-0.91 \mathrm{ppm}$ and multiplet at $\delta=1.29-1.43 \mathrm{ppm}$ were, respectively, ascribed to the methyl and methylene group $\left(-\mathrm{CH}_{2} \mathrm{CH}_{2} \mathrm{CH}_{3}\right)$ of longer alkyl chain. The triple at $\delta=$ $2.55-2.58 \mathrm{ppm}$ was assigned to the methylene $\left(-\mathrm{CH}_{2} \mathrm{COO}-\right)$ next to the ester group, while $\beta$-proton from the ester group ( $\left.-\underline{\mathrm{CH}}_{2} \mathrm{CH}_{2} \mathrm{COO}-\right)$ was found at $\delta=1.73-1.80 \mathrm{ppm}$ in the form of a quintet. The four doublets observed at $\delta=$ 6.5-8.0 ppm were attributed to aromatic protons of the two phenyl rings. Two doublets and one triplet observed at $\delta=7.69-8.01 \mathrm{ppm}$ were assigned to the 3 protons in the thiophene ring. The singlet at $\delta=8.46 \mathrm{ppm}$ supported the presence of imine linking group in the structure of the compound 3c [9].

By referring to the ${ }^{13} \mathrm{C}$ spectrum of $3 \mathrm{c}$ (Figure 2 ), the peak at range $\delta=22.68-34.43 \mathrm{ppm}$ was assigned to the methylene carbon of the longer alkyl chain, whereas the peak at $\delta=14.12$ ppm represents the methyl carbon of the longer alkyl chain. Sixteen aromatic carbons were found that resonated within $\delta=121.77-152.97 \mathrm{ppm}$ and four of the peaks were more intense compared to the other four peaks. This suggested that the high intensity peaks can be assigned to two equivalent aromatic carbons of the phenyl ring which had a 1,4-disubstitute structure. Peaks at $\delta=159.16 \mathrm{ppm}$ further confirmed the presence of azomethine carbon and it is compatible with the value as stated in the literature [17]. Meanwhile, peaks at $\delta=160.21$ and $172.45 \mathrm{ppm}$ indicated the presence of two carbonyl ester groups in the molecule [10,17].

Mesomorphic properties of the title compounds were observed through an optical polarizing microscope attached to a video camera. The optical micrograph of the mesophases of $\mathbf{3 b}$ and $\mathbf{3} \mathbf{g}$ was given in Figure 4 . The identification for the observed textures was then compared to previously reported samples $[18,19]$.

All the synthesized compounds exhibited enantiotropic nematic phase properties, with a higher-ordered monotropic SmC phase emerging from hexadecanoyloxy derivatives, while the enantiotropic SmC phase was observed in the octadecanoyloxy derivative. Representative optical photomicrographs of compounds $\mathbf{3 b}$ and $\mathbf{3 g}$ are shown in Figure 3. The presence of nematic in $\mathbf{3 b}$ (Figure 3(a)) was evidenced by a typical thread-like texture upon cooling of the compounds from the isotropic liquid phase. Upon further cooling of the homeotropic nematic phase (Figure 3(b)) of $3 \mathbf{g}$ to a lower temperature, a higher-order SmC was formed. 


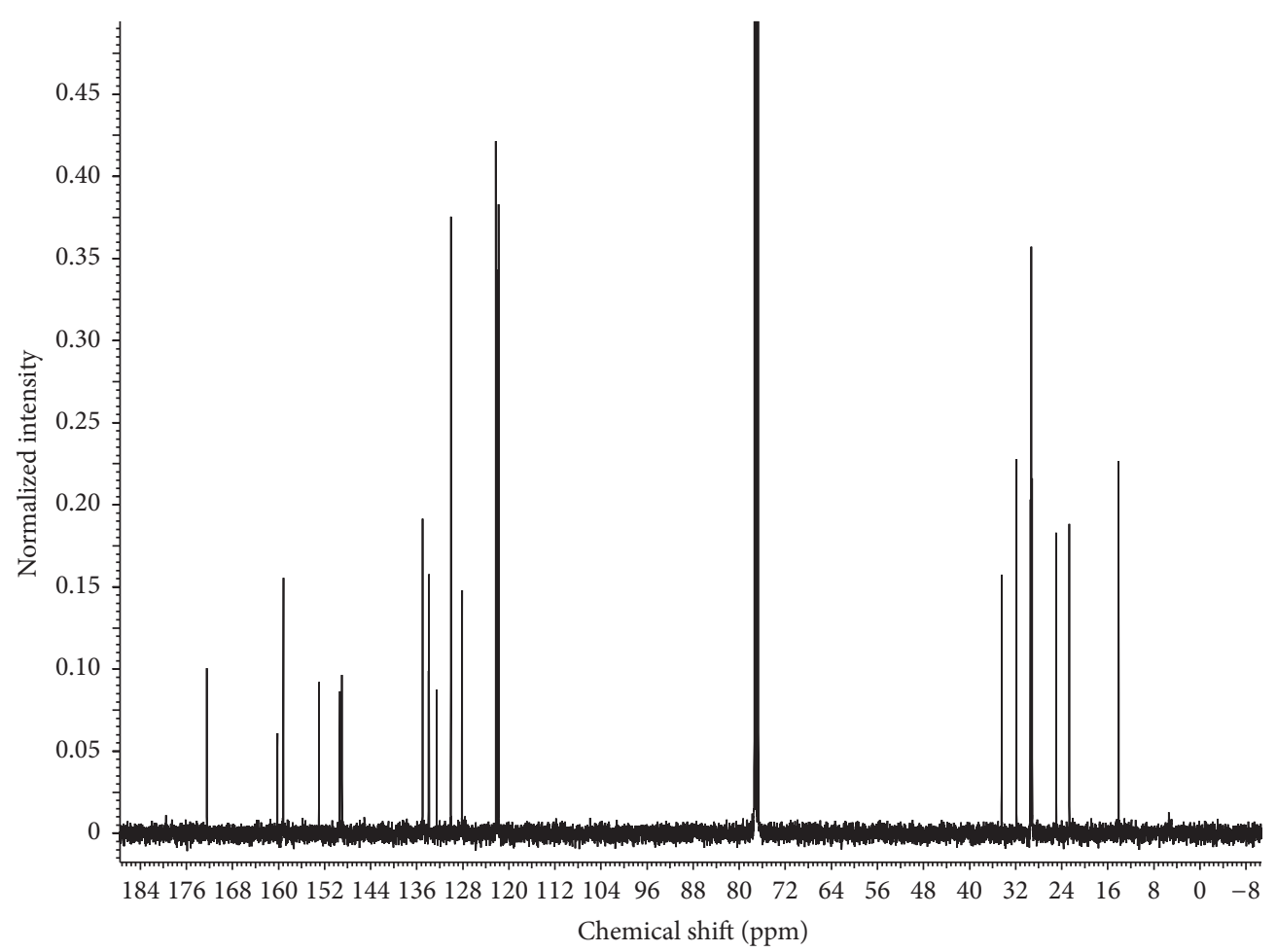

Figure 2: ${ }^{13} \mathrm{C}$ NMR spectra of $3 c$.

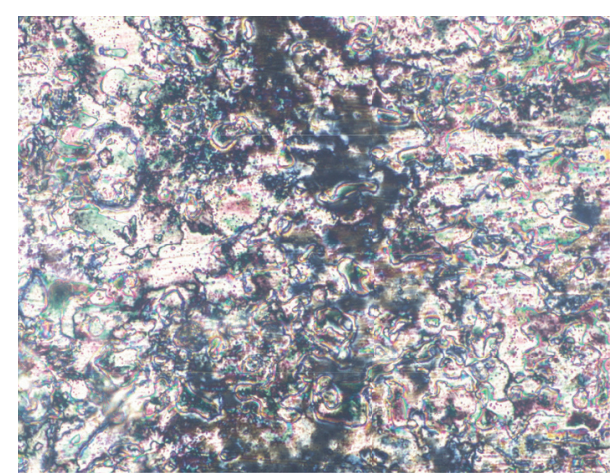

(a)

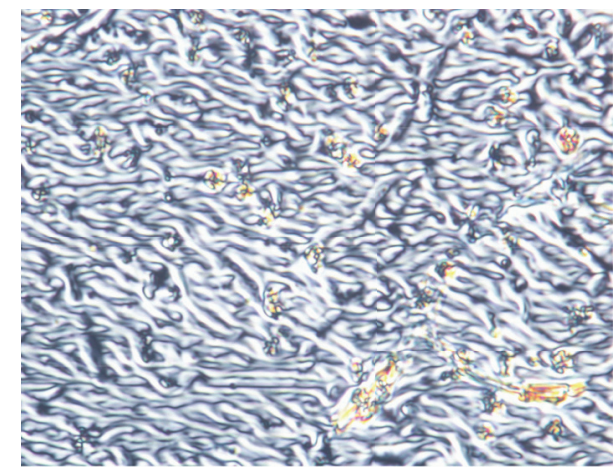

(c)

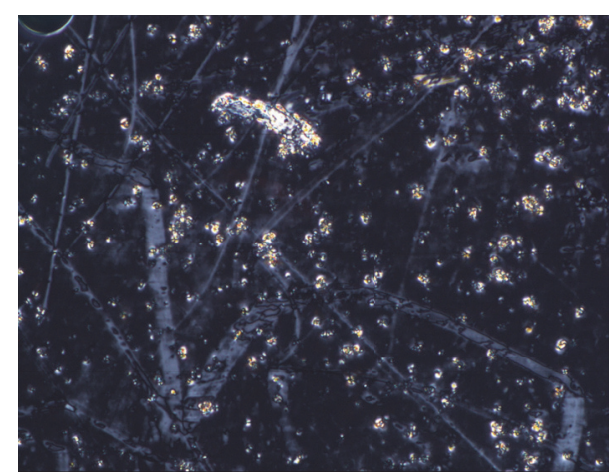

(b)

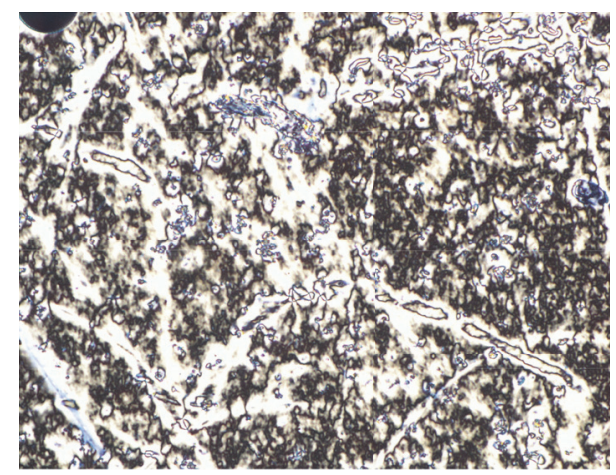

(d)

Figure 3: (a) Thread-like nematic at $103^{\circ} \mathrm{C}$ of $\mathbf{3 b}$ (20x magnificent). (b) Homeotropic nematic at $110^{\circ} \mathrm{C}$ of $3 \mathbf{g}$ (20x magnificent). (c) N-SmC transition bar at $105^{\circ} \mathrm{C}$ of $\mathbf{3 g}$ (20x magnificent). (d) Schlieren smectic $\mathrm{C}$ of at $98^{\circ} \mathrm{C}$ of $3 \mathbf{g}$ (20x magnificent). 


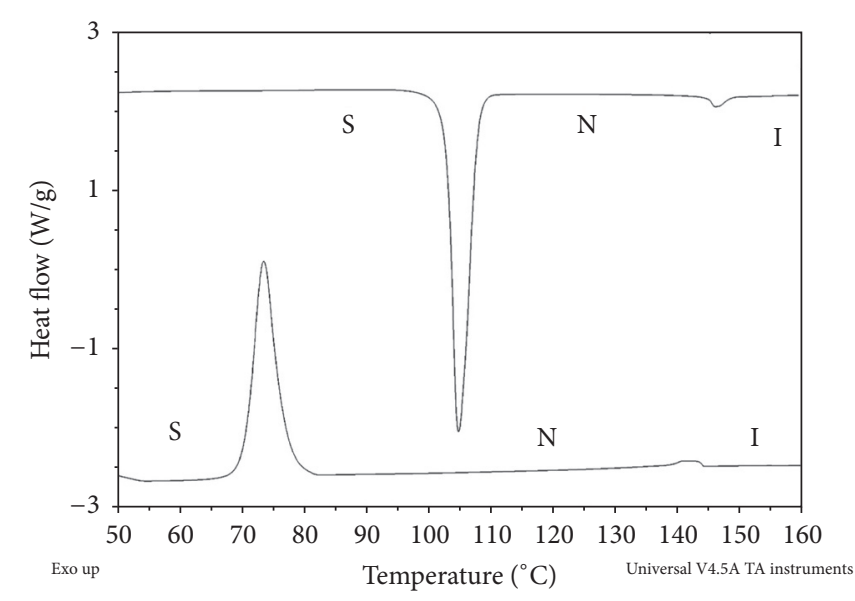

(a)

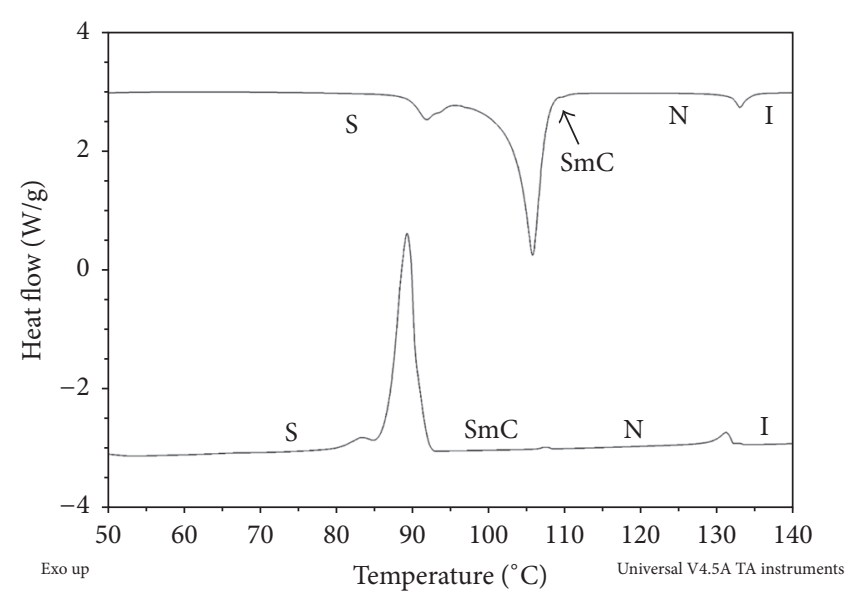

(b)

FIGURE 4: (a) DSC thermogram of $\mathbf{3 d}$. (b) DSC thermogram of $\mathbf{3 g}$.

TABLE 1: Phase transition temperature and transition enthalpy changes for compounds $\mathbf{3 a - g}$.

\begin{tabular}{|c|c|}
\hline Compound & Phase transition, ${ }^{\circ} \mathrm{C}$ (corresponding enthalpy changes, $\mathrm{kJmol}^{-1}$ ) \\
\hline \multirow{2}{*}{$3 \mathbf{a}$} & $\mathrm{Cr}_{1} 85.08(5.88) \mathrm{Cr}_{2} 95.43(24.65) \mathrm{N} 156.81(0.55) \mathrm{I}$ \\
\hline & I $156.69(0.47) N 75.86(20.72) \mathrm{Cr}$ \\
\hline \multirow{2}{*}{$3 b$} & Cr $104.75(38.67) \mathrm{N} 146.10$ (1.06) I \\
\hline & I $143.30(1.02) N 73.49$ (33.61) Cr \\
\hline \multirow{2}{*}{$3 c$} & $\mathrm{Cr}_{1} 84.45(0.95) \mathrm{Cr}_{2} 105.51(28.03) \mathrm{N} 141.04$ (1.09) I \\
\hline & I $136.30(0.71) \mathrm{N} 81.14(29.07) \mathrm{Cr}$ \\
\hline \multirow{2}{*}{$3 \mathbf{d}$} & $\mathrm{Cr}_{1} 89.51(0.81) \mathrm{Cr}_{2} 108.08(31.92) \mathrm{N} 142.25(0.91) \mathrm{I}$ \\
\hline & I $141.15(1.01) \mathrm{N} 84.53(34.72) \mathrm{Cr}$ \\
\hline \multirow{2}{*}{$3 \mathbf{e}$} & $\mathrm{Cr}_{1} 89.53(0.66) \mathrm{Cr}_{2} 108.96(38.21) \mathrm{N} 141.93$ (1.27) I \\
\hline & I $139.27(1.37) \mathrm{N} 82.90(40.61) \mathrm{Cr}$ \\
\hline \multirow{2}{*}{$3 f$} & $\mathrm{Cr}_{1} 100.34(3.88) \mathrm{Cr}_{2} 111.01(33.26) \mathrm{N} 135.67(2.10) \mathrm{I}$ \\
\hline & I 134.15 (2.37) N 105.48 (0.32) SmC 89.75 (47.45) Cr \\
\hline \multirow{2}{*}{$3 \mathrm{~g}$} & $\mathrm{Cr}_{1} 91.78(2.67) \mathrm{Cr}_{2} 105.76(32.30) \mathrm{SmC} 109.76(0.02) \mathrm{N} 132.92$ (2.01) I \\
\hline & I $131.05(1.60) \mathrm{N} 107.43(0.14) \mathrm{SmC} 90.82(42.39) \mathrm{Cr}$ \\
\hline
\end{tabular}

The characteristic transition bar texture (Figure 3(c)) [20], which usually appeared in the transition of a nematic phase into SmC phase, was observed there. This further confirmed the presence of the Schlieren smectic C-phase (Figure 3(d)).

The DSC results of compounds $\mathbf{3 a - 3} \mathbf{g}$ are consistent with the results obtained via polarizing microscopy in terms of transition temperatures for all heating and cooling cycles. The DSC traces of representative compounds $\mathbf{3} \mathbf{d}$ and $\mathbf{3 g}$ are given in Figures 4(a) and 4(b), respectively. The transition temperatures of the mesomorphic change data were tabulated in Table 1.

A plot of transition temperatures against the number of carbons in the alkanoyloxy chain during the heating cycle is shown in Figure 5. Firstly, it is evident that both melting $(\mathrm{Cr}-$ $\mathrm{SmC} / \mathrm{N})$ and clearing $(\mathrm{N}-\mathrm{I})$ points were greatly influenced by the length of alkanoyloxy chain in the compounds. The melting point of the title compounds showed an ascending trend as a function of the number of carbon atoms in the alkanoyloxy chain. This may be due to the increase in the van der Waals force as the size of the molecules is elongated. However, the clearing temperature-isotropic temperature is inversely proportional to the number of carbons. The additional number of carbon atoms in the terminal chain provides extra flexibility to the molecular structure. Secondly, a higher-ordered SmC phase was observed only in the homologous with relatively longer chain members, C18 in this case [21]. It can be understood that a longer terminal alkanoyloxy chain may favor the lamellar arrangement in the smectic layer structure due to the increased of van der Waals interactions and the possibilities of intertwining between alkanoyloxy chains [22]. Finally, the nematic phase range was reduced while the $\mathrm{SmC}$ phase range increased as the chain length increased. The increasing van der Waals attractive forces provide stronger lateral attractive interactions, which in turn resulted in the formation of layer packing. 


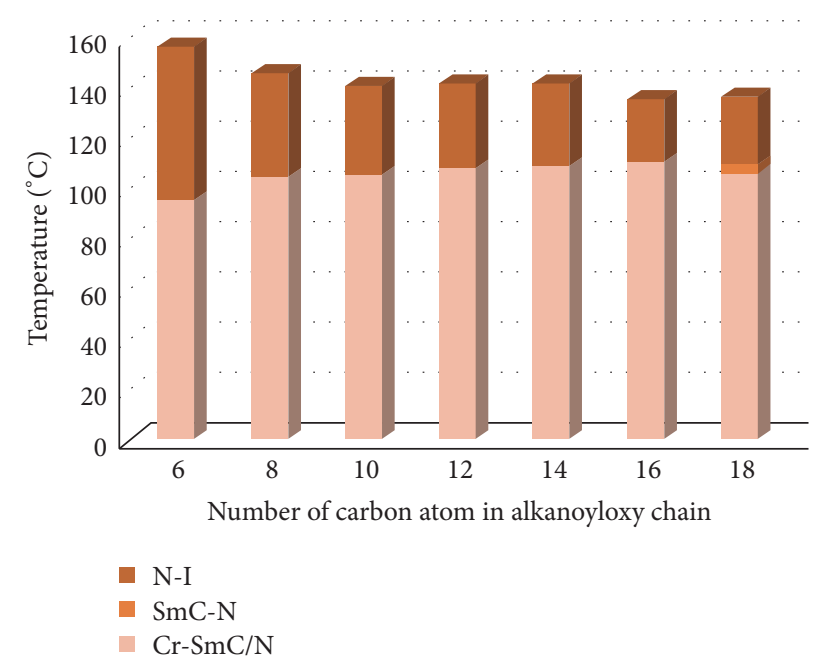

FIgURE 5: Transition temperatures against the number of carbons in the alkanoyloxy chain of the title compounds during the heating cycle.

\section{Conclusion}

All the synthesized compounds exhibited liquid crystal behavior, where nematic and SmC phases were observed. The length of the terminal alkanoyloxy chain has greatly influenced the properties of the liquid crystal, such as melting and clearing isotropic temperatures and liquid crystal phase ranges. This can be shown where the title compounds exhibit enantiotropic $\mathrm{N}$ phase with relatively high thermal stability $\left(>30^{\circ} \mathrm{C}\right)$ and the existence of smectic $\mathrm{C}$ for the longer carbon chain compounds $(n>14)$. Even numbers of flexible chain were chosen as the intermolecular attractive forces of the even number compounds are stronger as compared to the odd numbers compounds due to its molecular structure conformation which are more linear. Heterocyclic such as thiophene is an essential core unit as it will enhance the mesomorphic properties and greater anisotropy properties of the liquid crystal materials. For future work, we will rearrange and modify the molecular structure of the homologous series for higher thermal stable liquid crystal compounds by introducing the thiophene rings in the middle of core unit which is expected to provide a bent shape of core unit.

\section{Competing Interests}

The authors declare that there is no conflict of interests regarding the publication of this paper.

\section{Acknowledgments}

The authors would like to thank the University of Malaya (UM) for the research facilities and financial support through Postgraduate Research Fund (PPP) with the vote PG0132013A and Fundamental Research Grant Scheme (FRGS) with the vote FP031-2014B.

\section{References}

[1] B. B. Eran, A. Nesrullajev, and N. Y. Canli, "Characterization and investigation of the mesogenic, thermo-morphologic and thermotropic properties of new chiral $(S)$-5-octyloxy-2-[4-(2methylbuthoxy)-phenyliminomethyl]phenol liquid crystalline compound," Materials Chemistry and Physics, vol. 111, no. 2-3, pp. 555-558, 2008.

[2] F. Artzner, M. Veber, M. Clerc, and A.-M. Levelut, "Evidence of nematic, hexagonal and rectangular columnar phases in thermotropic ionic liquid crystals," Liquid Crystals, vol. 23, no. 1, pp. 27-33, 1997.

[3] H. B. Li, X. Zhang, R. F. Zhang, J. C. Shen, B. Zhao, and W. Q. $\mathrm{Xu}$, "Thermotropic liquid crystalline behavior of an amphiphilic polymer lacking mesogens," Macromolecules, vol. 28, no. 24, pp. 8178-8181, 1995.

[4] G. F. Starkulla, E. Kapatsina, A. Baro et al., "Influence of spacer chain lengths and polar terminal groups on the mesomorphic properties of tethered 5-phenylpyrimidines," Beilstein Journal of Organic Chemistry, vol. 5, article no. 63, 2009.

[5] Z. Wu, Z. Zhen, J.-H. Jiang, G.-L. Shen, and R.-Q. Yu, “Terminal protection of small-molecule-linked DNA for sensitive electrochemical detection of protein binding via selective carbon nanotube assembly," Journal of the American Chemical Society, vol. 131, no. 34, pp. 12325-12332, 2009.

[6] T.-M. Koh, S.-T. Ha, G.-Y. Yeap, and H.-C. Lin, "New mesomorphic benzothiazol derivatives: synthesis and characterization," Chinese Chemical Letters, vol. 24, no. 10, pp. 926-928, 2013.

[7] S. T. Ha, K. L. Foo, H. C. Lin et al., "Mesomorphic behavior of new benzothiazole liquid crystals having Schiff base linker and terminal methyl group," Chinese Chemical Letters, vol. 23, no. 7, pp. 761-764, 2012.

[8] T. M. Koh, S. T. Ha, T. L. Lee et al., "Synthesis and mesomorphic evaluation of new calamitic liquid crystals containing benzothiazole core," Chinese Chemical Letters, vol. 22, no. 5, pp. 619-622, 2011.

[9] S.-T. Ha, T.-M. Koh, S.-L. Lee, G.-Y. Yeap, H.-C. Lin, and S.-T. Ong, "Synthesis of new schiff base ester liquid crystals with a benzothiazole core," Liquid Crystals, vol. 37, no. 5, pp. 547-554, 2010.

[10] S. T. Ha, K. L. Foo, R. T. Subramaniam, M. M. Ito, S. S. Sastry, and S. T. Ong, "Heterocyclic benzoxazole-based liquid crystals: synthesis and mesomorphic properties," Chinese Chemical Letters, vol. 22, no. 10, pp. 1191-1194, 2011.

[11] G. Shanker and C. Tschierske, "Synthesis of non-symmetrically substituted 1,2,4-oxadiazole derived liquid crystals," Tetrahedron, vol. 67, no. 45, pp. 8635-8638, 2011.

[12] M. L. Rahman, G. Hegde, M. M. Yusoff, M. N. F. A. Malek, H. T. Srinivasa, and S. Kumar, "New pyrimidine-based photoswitchable bent-core liquid crystals," New Journal of Chemistry, vol. 37, no. 8, pp. 2460-2467, 2013.

[13] L. Soria, P. Ovejero, M. Cano et al., "Selecting pyrazole-based silver complexes for efficient liquid crystal and luminescent materials," Dyes and Pigments, vol. 110, pp. 159-168, 2014.

[14] S.-T. Ha, T.-M. Koh, H.-C. Lin et al., "Heterocyclic benzothiazole-based liquid crystals: synthesis and mesomorphic properties," Liquid Crystals, vol. 36, no. 9, pp. 917-925, 2009.

[15] D. R. Dos Santos, A. G. S. De Oliveira, R. L. Coelho, I. M. Begnini, R. F. Magnago, and L. D. Silva, "Synthesis of liquid crystals materials derived from oxadiazole, isoxazole and tetrazole heterocycles," ARKIVOC, vol. 2008, no. 17, pp. 157-166, 2008. 
[16] D. Srividhya, S. Manjunathan, and S. Thirumaran, "Synthesis and characterization of new heterocyclic liquid crystals," $E$ Journal of Chemistry, vol. 6, no. 3, pp. 928-937, 2009.

[17] G.-Y. Yeap, T.-C. Hng, D. Takeuchi, K. Osakada, W. Ahmad Kamil Mahmood, and M. M. Ito, "Non-symmetric liquid crystal dimers: high thermal stability in nematic phase enhanced by thiophene-2-carboxylate moiety," Molecular Crystals and Liquid Crystals, vol. 506, no. 1, pp. 134-149, 2009.

[18] D. Demus and L. Ritcher, Textures of Liquid Crystals, Verlag Chemie, New York, NY, USA, 1978.

[19] L. Dierking, Textures of Liquid Crystals, Wiley-Verlag GmbH \& Co, Weinheim, Germany, 2003.

[20] G. W. Gray and J. W. G. Goodby, Smectic Liquid CrystalsTextures and Structures, Leonard Hill, Glasgow, Scotland, 1984.

[21] G.-Y. Yeap, S.-T. Ha, P.-L. Lim et al., "Nematic and smectic a phases in ortho-hydroxy-para-hexadecanoyloxbenzylidenepara-substituted anilines," Molecular Crystals and Liquid Crystals, vol. 452, no. 1, pp. 63-72, 2006.

[22] K.-L. Foo, S.-T. Ha, and S.-L. Lee, "Synthesis and characterization of thermotropic liquid crystals consisting heterocyclic benzothiazole core system," Asian Journal of Chemistry, vol. 26, no. 22, pp. 7627-7631, 2014 

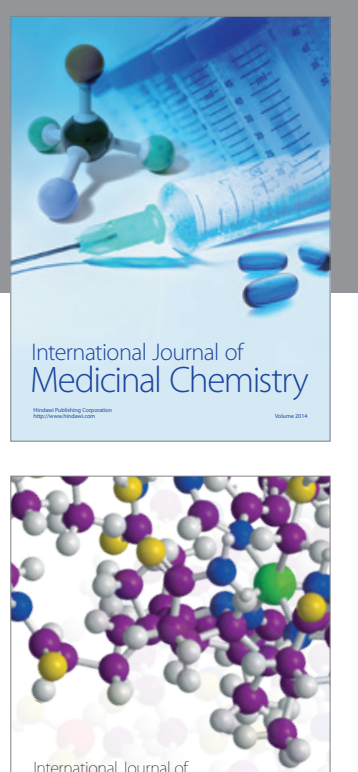

Carbohydrate Chemistry

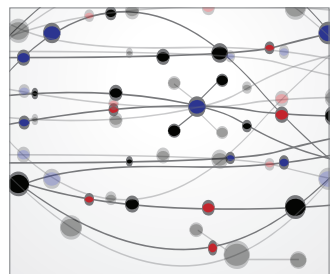

The Scientific World Journal
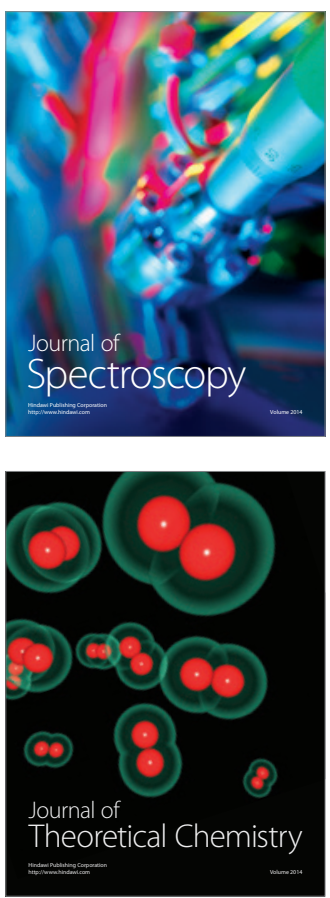
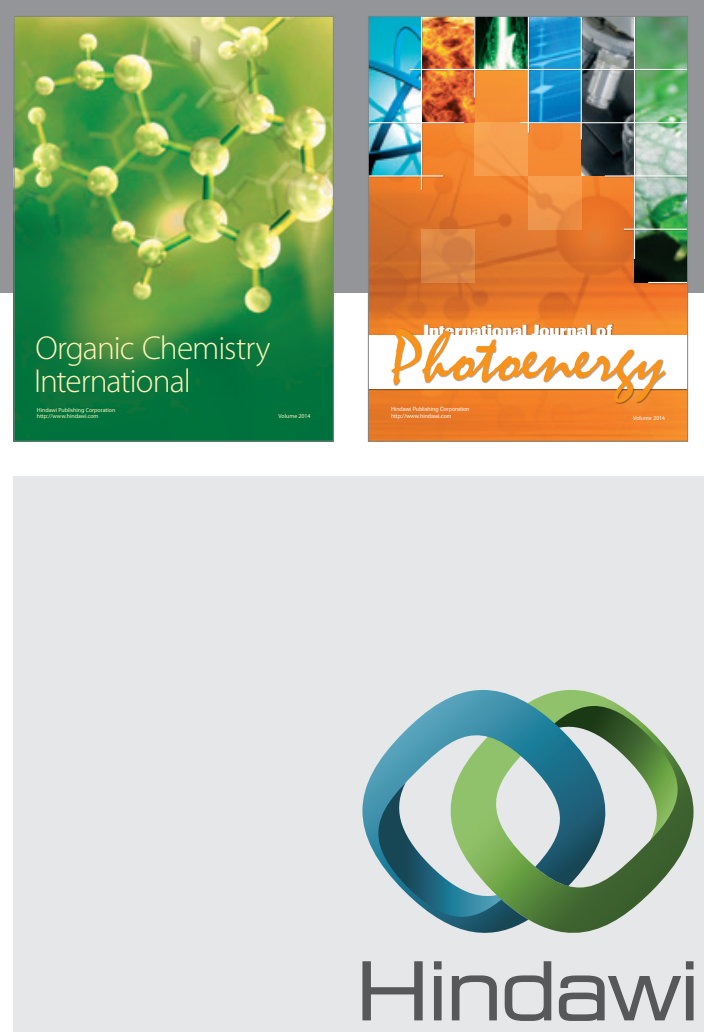

Submit your manuscripts at

http://www.hindawi.com

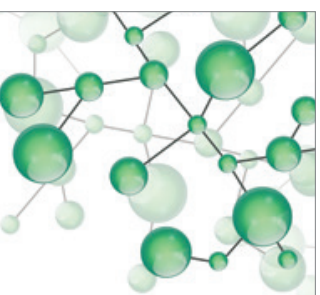

International Journal of

Inorganic Chemistry

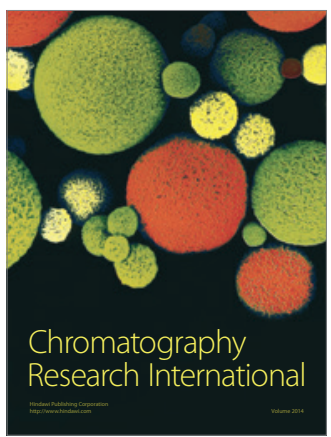

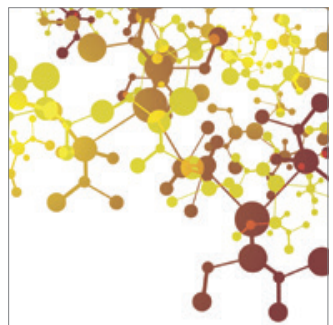

Applied Chemistry
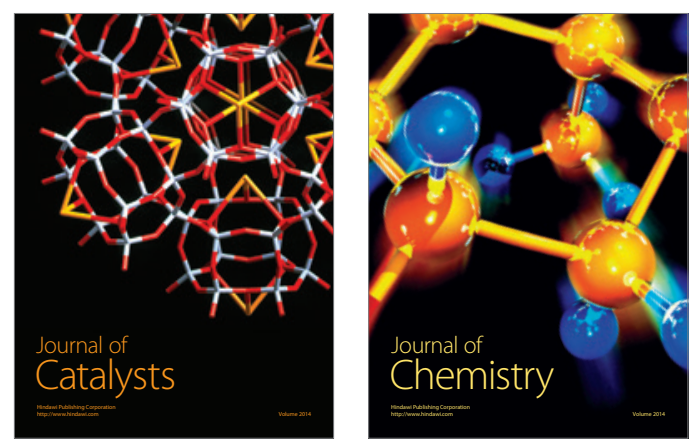
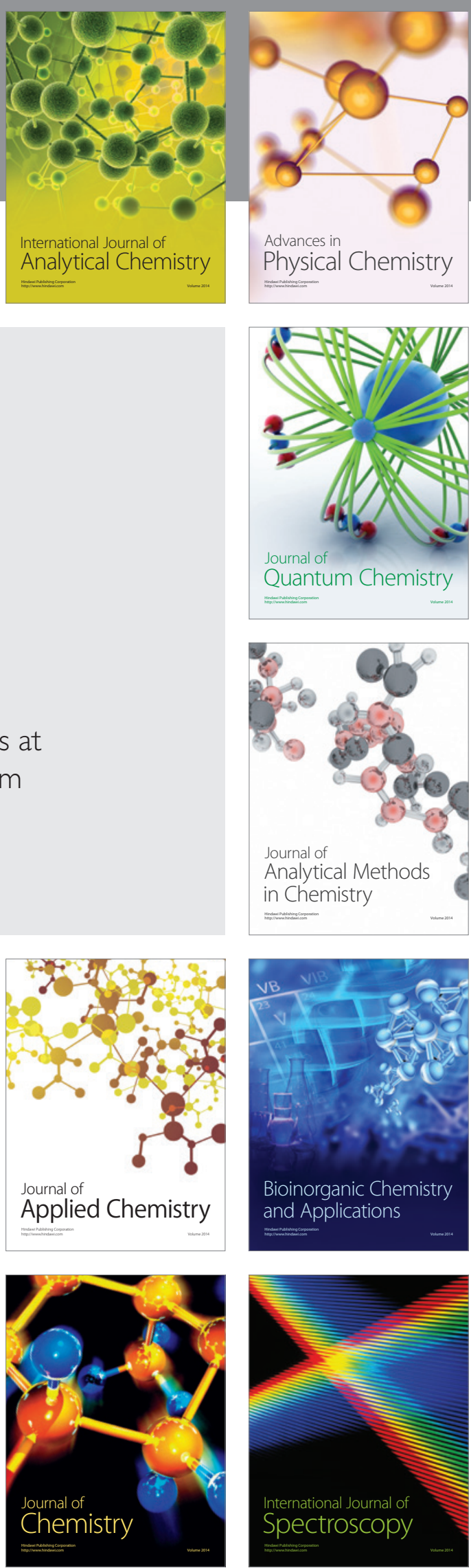